\title{
Prognostic Role of Tissue and Circulating MicroRNA-200c in Malignant Tumors: a Systematic Review and Meta-Analysis
}

\author{
Yingjie Shao ${ }^{a}$ Yiting Geng ${ }^{b} \quad$ Wendong $\mathrm{Gu}^{\mathrm{a}}$ Jin Huang ${ }^{\mathrm{a}}$ Honglei Peia \\ Jingting Jiang ${ }^{c}$
}

aDepartment of Radiation Oncology, bDepartment of Oncology, 'Department of Tumor Biological Treatment, The Third Affiliated Hospital of Soochow University, Changzhou, P.R. China

\section{Key Words}

MicroRNA-200c • Cancer • Prognosis • Meta-analysis

\begin{abstract}
Background: Recently, many studies have shown that microRNAs (miRNA) exhibit altered expression in various cancers and may serve as prognostic biomarkers. We performed a systematic review and meta-analysis to evaluate the prognostic role of miR-200c expression in different cancers. Methods: Studies were recruited by searching PubMed, Embase and the Cochrane Library (last search update was May 2014) and assessed by further quality evaluation. Results: A total of 25 studies dealing with various carcinomas were identified for systematic review. Among them, 18 studies were ultimately included in the meta-analysis. Our results indicated that the expression of tissue miR-200c was not associated with OS and PFS in various carcinomas; however, downregulation of tissue miR-200c did predict poor OS of patients with stage I disease $(\mathrm{HR}=0.41,95 \% \mathrm{CI} 0.25-0.68, P=0.001)$. Furthermore, overexpression of blood miR-200c was significantly related to poor OS and PFS (HR=3.07 95\% CI 1.58-5.96 P=0.001, $\mathrm{HR}=2.2695 \% \mathrm{CI} 1.66-3.08 \mathrm{P}<0.001$, respectively), especially in patients with advanced disease. Conclusion: This systematic review and meta-analysis clarified that low expression of miR$200 \mathrm{c}$ in primary tissue was significantly associated with poor survival in cancer patients at early stage, whereas a high level of blood miR-200c predicted poor prognosis in patients with advanced tumors.
\end{abstract}




\section{Introduction}

MicroRNAs (miRNAs) are small non-coding RNAs that post-transcriptionally regulate gene expression. It has been found that numerous miRNAs exhibit misregulated expression in multiple types of cancers and are often associated with diagnosis, staging, progression, prognosis and response to clinical therapies (reviewed in [1]). The miR-200 family includes five members: miR-200a, miR-200b, miR-200c, miR-429 and miR-141. It plays a critical regulatory role in two processes which are associated with metastasis and prognosis of malignant tumors: epithelial-to-mesenchymal transition (EMT) and mesenchymal-toepithelial transition (MET) [2-5]. EMT is a reversible series of events in which an epithelial cell loses cell-cell contact and acquires mesenchymal properties [6]. The miR-200 family is a key regulator of the epithelial phenotype by directly targeting two transcriptional repressors of E-cadherin (encoded by CDH1): ZEB1 and ZEB2 (also named TCF8 and SIP1). Deficiencies in miR-200 expression will lead to the accumulation of ZEB1 and ZEB2, and subsequently silence the CDH1 and promote EMT [2,3]. MET is the reverse process of EMT. The miR-200 family is overexpressed during MET, then inhibits ZEB1 and ZEB2 expression and promotes the synthesis of E-cadherin [4,5].

MiR-200c is the most representative miRNA among the miR-200 family. It plays a critical role in the regulation of both the EMT and MET processes [4, 7]. Since 2006 [8], multiple studies have demonstrated the prognostic value of miR-200c in different cancers, including serous ovarian cancer [9], bladder cancer [10], pancreatic cancer [11], esophageal cancers [12], lung cancer [13] and endometrial cancer [14]. Nearly half of these studies revealed a significant association between miR-200c overexpression and poor prognosis $[8,9,13,15$ 22]. However, other studies reported an insignificant association or opposite conclusions [10-12, 14, 23-30]. The evidence from individual study is insufficient to conclude whether miR-200c can be used as a potent biomarker for prognosis. Consequently, a systematic and comprehensive meta-analysis is urgently required to explore the relationship between miR200c expression and prognosis of cancer patients.

Through a systematic review and meta-analysis of global literatures, this study performed a comprehensive and objective evaluation of the prognostic significance of elevated tissue- and blood-based miR-200c levels in cancer patients. Moreover, we analyzed the underlying mechanism for the regulatory roles of miR-200c in EMT and MET that are associated with tumor metastasis and patient prognosis.

\section{Materials and Methods}

This meta-analysis was carried out in accordance with the Systematic Reviews and Meta-Analyses (PRISMA) and the Observational Studies in Epidemiology (MOOSE) guidelines [31].

\section{Search strategy}

Literatures were searched through PubMed, Embase and the Cochrane Library (last update by May 20, 2014). Keywords used in the search strategy were "microRNA-200c OR miR-200c" (all fields) AND "tumor OR tumour OR neoplasm OR cancer OR carcinoma" (all fields). We did not impose any advanced limitations when searching the database. The reference lists of identified articles were also screened to further identify potential studies. The comprehensive database search was carried out independently by two authors (Y. Shao and Y. Geng).

\section{Inclusion and exclusion criteria}

Literatures that were eligible for inclusion in this systematic review met the following criteria: (1) the expression of miR-200c in cancer tissue or blood, (2) investigation of the relationship between miR200c expression level and survival outcome. Studies with sample size $\geq 30$ and provided sufficient data to estimate the hazard ratio (HR) and 95\% confidence intervals (CI) were advanced to inclusion in the meta-analysis. Considering the tumorigenesis and metastasis mechanism of hematological malignancy is 
Shao et al.: Prognostic Value of MicroRNA-200c in Tumors

different from other tumors of epithelial origin, studies of hematological malignancy were excluded. When multiple studies reported on the same patient cohort, only the most recent or complete study was selected. Case reports, letters, reviews, conference abstracts and animal trials were excluded. Two reviewers independently evaluated titles and abstracts of the identified articles and subsequently excluded those that were considered irrelevant. The full text of enrolled articles was carefully examined for comprehensive evaluation. Disagreement from two reviews was resolved by consensus.

\section{Data extraction and quality assessment}

The required information from all eligible studies was collected by two researchers independently, which included first author's surname, publication year, origin of population, tumor type, sample number, tumor stage, lymph node metastasis, follow-up period, source of miRNA, miR-200c assessment methods and the cut-off definition, and HR of miR-200c expression for overall survival (OS), disease-free survival (DFS) and relapse-free survival (PFS) as well as corresponding 95\% CIs. If a study reported both the results of univariate and multivariate analysis, only the latter was selected because it has increased precision due to accounting for confounding factors.

The quality of each study was assessed independently by two researchers according to the NewcastleOttawa Quality Assessment Scale (NOS) [32]. For quality assessment, scores ranged from 0 (lowest) to 9 (highest), and studies with scores of 6 or more were rated as high quality.

\section{Statistical analysis}

High and low expression of miR-200c was defined according to the cut-off values provided in the articles. HRs and their 95\% CIs were combined to measure the effective value of miR-200c expression on prognosis. If the statistical variables were described in the study, we extracted them directly. Otherwise, they were calculated from available numerical data in the articles according to the methods described by Tierney [33]. The data from Kaplan-Meier survival curves were read by Engauge Digitizer version 4.1, and three independent researchers read the curves to reduce reading variability. We also sent e-mail to the corresponding authors of eligible articles requesting additional information and original data needed for the meta-analysis. An observed HR greater than 1 indicated a worse prognosis in patients with miR-200c overexpression and HR less than 1 suggested a better prognosis. Statistical heterogeneity was assessed by visual inspection of forest plots, by performing the Chi-square test (assessing the $P$ value), and by calculating the $I^{2}$ statistic $[34,35]$. If the $P$ value was less than 0.05 and/or $I^{2}$ exceeded $50 \%$, indicating the presence of heterogeneity, a random-effects model (the DerSimonian-Laird method) was used. Otherwise, the fixedeffects model (the Mante-Haenszel method) was used. Subgroup analysis and meta-regression were further performed to explore the source of identified heterogeneity. Publication bias was estimated by visually assessing the asymmetry of an inverted funnel plot. Furthermore, Begg's and Egger's tests were performed to provide quantitative evidence of publication bias. If publication bias was observed, we adjusted for the effect by the use of the Duval and Tweedie trim-and-fill method [36]. For all analyses, STATA version 12.0 (Stata Corporation, College Station, TX, USA) was used with significance defined as a $P$-value of less than 0.05 except where otherwise specified.

\section{Results}

\section{Study characteristics}

Using the described searching strategy, 787 references were initially retrieved. After screening the titles, abstracts, publication types and full text of each publication, 23 articles including 25 studies that investigated the correlation between miR-200c expression and patient survival or disease recurrence in various malignant tumors were selected for the systemic review (Table 1). A total of 2,534 patients from the United Kingdom, Germany, Spain, Poland, Japan, Sweden, Korea, Norway, Denmark, Italy, USA, China and Chinese Taiwan were diagnosed with a variety of cancers, including esophageal cancer $[12,19,27]$, gastric cancer $[16,25,28]$, colorectal cancer [8, 20, 29], rectal cancer [30], hepatocellular carcinoma [26], pancreatic cancer [11], lung cancer [13], breast cancer [15], diffuse large B-cell lymphoma (DLBCL) [18], bladder cancer [10], endometrial cancer [14, 17], ovarian 
Table 1. The main characteristic of all studies in the systematic review. qRT-PCR - quantitative real-time PCR, ISH - in situ hybridization, OS - overall survival, DFS - disease-free survival, PFS - progression-free survival, HR - hazard ratio, SC - survival curve, NR - not reported, NSCLC - non-small cell lung cancer, Ref. reference

\begin{tabular}{|c|c|c|c|c|c|c|c|c|c|c|c|c|c|c|}
\hline Study & $\begin{array}{l}\text { Case } \\
\text { nationality }\end{array}$ & Tumor type & $\begin{array}{l}\text { Sample } \\
\text { number }\end{array}$ & $\begin{array}{l}\text { Tumor stage } \\
\text { I/II/III/IV }\end{array}$ & $\begin{array}{l}\text { Lymph } \\
\text { node } \\
-/^{+}\end{array}$ & $\begin{array}{l}\text { Follow-up } \\
\text { months }\end{array}$ & $\begin{array}{l}\text { Detected } \\
\text { sample }\end{array}$ & $\begin{array}{l}\text { MiR-200c } \\
\text { assay }\end{array}$ & $\begin{array}{l}\text { Cut-off } \\
\text { definition }\end{array}$ & $\begin{array}{l}\text { Multivariate } \\
\text { analysis }\end{array}$ & $\begin{array}{l}\text { Survival } \\
\text { analysis }\end{array}$ & $\begin{array}{l}\text { Meta } \\
\text { analysis }\end{array}$ & $\begin{array}{l}\text { Hazard } \\
\text { ratios }\end{array}$ & Ref. \\
\hline Xi 2006 & USA & colorectal cancer & 25 & $4 / 4 / 8 / 8$ & NR & over 50 & tissue & qRT-PCR & $\mathrm{dCT}=4.54$ & NO & os & NO & - & {$[8]$} \\
\hline Nam 2008 & Korea & ovarian cancer & 20 & $\mathrm{NR}$ & NR & NR & tissue & qRT-PCR & NR & No & os & No & - & [9] \\
\hline Wiklund 2011 & Denmark & bladder cancer & 100 & $100 / 0 / 0 / 0$ & $0 / 100$ & over 40 & tissue & ISH & NR & No & os & YES & sc & [10] \\
\hline Yu 2010 & Japan & pancreatic cancer & 99 & $9 / 85 / 1 / 4$ & $33 / 66$ & over 60 & tissue & qRT-PCR & 0.64 & YES & os & YES & sc & [11] \\
\hline Hamano 2011 & Japan & esophageal cancer & 98 & $6 / 28 / 28 / 36$ & $29 / 69$ & $\begin{array}{l}\text { median 28.8 } \\
(2.3-96.7)\end{array}$ & tissue & qRT-PCR & median & No & os & YES & sc & [12] \\
\hline Liu 2012 & China & NSCLC & 70 & I36/II-III-IV34 & $38 / 32$ & 24 & tissue & qRT-PCR & fold change $=2$ & No & os & YES & report & [13] \\
\hline $\begin{array}{l}\text { Karaayvaz } \\
2012\end{array}$ & USA & $\begin{array}{l}\text { endometrial } \\
\text { cancer }\end{array}$ & 48 & $26 / 4 / 6 / 12$ & $\mathrm{NR}$ & 125 & tissue & qRT-PCR & $\mathrm{dCT}=35.5$ & No & os & YES & sc & [14] \\
\hline $\begin{array}{l}\text { Madhavan } \\
2012\end{array}$ & Germany & breast Cancer & 164 & IIII-IV164 & NR & 24 & plasma & qRT-PCR & lower quartile & NO & OS, PFS & YES & SC & [15] \\
\hline $\begin{array}{l}\text { Valladares } \\
\text { Ayerbes } 2012\end{array}$ & Spain & gastric cancer & 52 & I-II9/III12/IV31 & $9 / 24$ & over 50 & blood & qRT-PCR & mean & YES & OS, PFS & YES & report & [16] \\
\hline Torres 2013 & Poland & $\begin{array}{l}\text { endometrial } \\
\text { cancer }\end{array}$ & 73 & $50 / 5 / 20 / 2$ & $15 / 29$ & NR & tissue & qRT-PCR & median & YES & os & YES & report & [17] \\
\hline Berglund 2013 & Sweden & DLBCL & 61 & I-II25/III-IV36 & NR & over 60 & tissue & qRT-PCR & mean & No & os & No & sc & [18] \\
\hline Tanaka 2013 & Japan & esophageal cancer & 64 & III25/III-IV39 & $16 / 48$ & median 24 & serum & qRT-PCR & median & YES & PFS & YES & report & [19] \\
\hline Toiyama 2014 & Japan & colorectal cancer & 182 & IIII-IV182 & $105 / 77$ & over 60 & serum & qRT-PCR & median & YES & os & YES & report & [20] \\
\hline Toiyama 2014 & Japan & colorectal cancer & 156 & IIII-IV156 & $77 / 69$ & over 60 & tissue & qRT-PCR & median & No & os & YES & report & [20] \\
\hline $\begin{array}{l}\text { Vilming Elgaaen } \\
2014\end{array}$ & Norway & ovarian cancer & 35 & $0 / 0 / 25 / 10$ & $\mathrm{NR}$ & over 100 & tissue & qRT-PCR & tertiles & No & os & NO & - & [21] \\
\hline Leskela 2011 & Spain & ovarian cancer & 72 & $3 / 5 / 54 / 10$ & NR & NR & tissue & qRT-PCR & NR & YES & os & No & . & [23] \\
\hline Marchini 2011 & Italy & ovarian cancer & 89 & $89 / 0 / 0 / 0$ & $89 / 0$ & $\begin{array}{l}\text { median } 110 \\
(84-139)\end{array}$ & tissue & qRT-PCR & median & YES & OS, PFS & YES & report & [24] \\
\hline Marchini 2011 & Italy & ovarian cancer & 55 & $55 / 0$ & $55 / 0$ & $\begin{array}{l}\text { median } 108 \\
(73-144)\end{array}$ & tissue & qRT-PCR & median & YES & OS, PFS & YES & report & [24] \\
\hline Tang 2013 & China & gastric cancer & 126 & I-III51/III-IV75 & $38 / 88$ & 50 & tissue & ISH & $\begin{array}{l}\text { expression } \\
\text { scores }>2\end{array}$ & YES & OS, DFS & YES & report & [25] \\
\hline Yeh 2014 & Taiwan & $\begin{array}{l}\text { hepatocellular } \\
\text { carcinoma }\end{array}$ & 90 & $\mathrm{NR}$ & $\mathrm{NR}$ & 36 & tissue & qRT-PCR & NR & YES & OS, DFS & NO & - & [26] \\
\hline Yu 2013 & China & esophageal cancer & 164 & $0 / 0 / 86 / 71$ & $0 / 164$ & over 50 & serum & qRT-PCR & median & YES & os & YES & report & [27] \\
\hline Song 2014 & China & gastric cancer & 364 & $4 / 123 / 111 / 147$ & $127 / 258$ & $\begin{array}{l}{ }_{(1-112)}^{\operatorname{median}} 35 \\
\end{array}$ & tissue & qRT-PCR & median & YES & os, PFS & YES & report & [28] \\
\hline Diaz 2014 & Spain & colorectal cancer & 127 & $0 / 18 / 64 / 45$ & $82 / 45$ & median 113 & tissue & qRT-PCR & median & YES & OS, DFS & YES & sc & [29] \\
\hline Bhangu 2014 & UK & rectal cancer & 103 & $25 / 44 / 34 / 0$ & $69 / 34$ & NR & tissue & ISH & NR & No & OS, DFS & No & - & [30] \\
\hline $\operatorname{Lin} 2014$ & Australia & prostate cancer & 97 & $0 / 0 / 11 / 86$ & $\mathrm{NR}$ & $\begin{array}{l}\text { median } 12 \\
(3-62)\end{array}$ & blood & qRT-PCR & median & No & os & YES & report & [22] \\
\hline
\end{tabular}

Fig. 1. Flow diagram of the study selection process

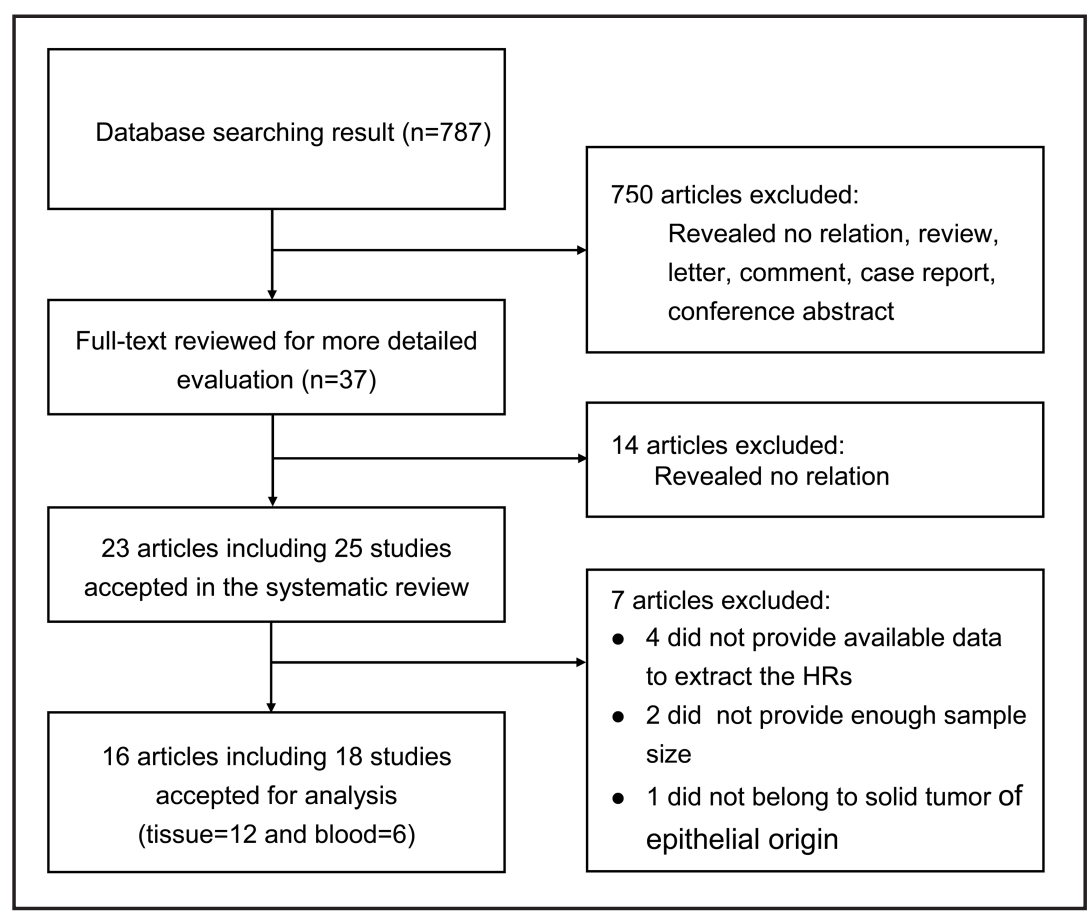

cancer $[9,21,23,24]$ and prostate cancer[22]. In the primary reports, 11 studies showed a significant association between high miR-200c and poor prognosis [8, 9, 13, 15-22], 9 provided the opposite result $[10,11,24-27,29,30]$ and 5 found no prognostic value of miR200c for tumor patients $[12,14,20,23,28]$. The expression of miR-200c was most often detected in tumor tissue samples, while five studies tested it in plasma or serum $[15,16$, 
Table 2. HRs and corresponding 95\% CIs of eligible studies in the meta-analysis according to tissuebased miR-200c overexpression. qRT-PCR - quantitative real-time PCR, ISH - in situ hybridization, OS - overall survival, DFS - disease-free survival, PFS - progression-free survival, HR - hazard ratio, CI confidence interval, NR - not reported, NSCLC - non-small cell lung cancer, DLBCL - diffuse large B-cell lymphoma, Ref. - reference

\begin{tabular}{|c|c|c|c|c|c|}
\hline Study & Tumor type & MiR-200c assay & $\begin{array}{l}\text { OS } \\
\text { HR }(95 \% \mathrm{CI})\end{array}$ & $\begin{array}{l}\text { PFS / DFS } \\
\text { HR }(95 \% \text { CI })\end{array}$ & Ref. \\
\hline Wiklund 2011 & bladder cancer & ISH & $0.52(0.29,0.93)$ & NR & [10] \\
\hline Yu 2010 & pancreatic cancer & qRT-PCR & $0.65(0.34,1)$ & NR & [11] \\
\hline Hamano 2011 & esophageal cancer & qRT-PCR & $1.68(0.95,2.96)$ & NR & [12] \\
\hline Liu 2012 & NSCLC & qRT-PCR & $6.02(1.344,26.971)$ & NR & [13] \\
\hline Karaayvaz 2012 & endometrial cancer & qRT-PCR & $1.31(0.56,3.09)$ & NR & [14] \\
\hline Torres 2013 & endometrial cancer & qRT-PCR & $2.723(1.47,5.043)$ & NR & [17] \\
\hline Toiyama 2014 & colorectal cancer & qRT-PCR & $0.56(0.28,1.1)$ & NR & [20] \\
\hline Marchini 2011 & ovarian cancer & qRT-PCR & $0.244(0.076,0.785)$ & PFS $0.419(0.146,1.204)$ & [24] \\
\hline Marchini 2011 & ovarian cancer & qRT-PCR & $0.094(0.012,0.766)$ & PFS $0.035(0.004,0.311)$ & [24] \\
\hline Tang 2013 & gastric cancer & ISH & $0.4(0.27,0.82)$ & DPS $0.51(0.39,0.87)$ & [25] \\
\hline Song 2014 & gastric cancer & qRT-PCR & $1.32(0.82,2.12)$ & PFS $1.06(0.7,1.6)$ & [28] \\
\hline Diaz 2014 & colorectal cancer & qRT-PCR & $0.46(0.23,0.93)$ & DFS $0.54(0.28,1.04)$ & [29] \\
\hline
\end{tabular}

Fig. 2. Forest plots of studies evaluating hazard ratios of tissue-based high miR-200c expression (a) Overall survival based on tissue miR-200c. The survival data from 13 studies were pooled to calculate overall survival. (b) In the subgroup analysis of patients with stage I cancer, the fixed effect analysis model was used to calculate the pooled HRs for OS.

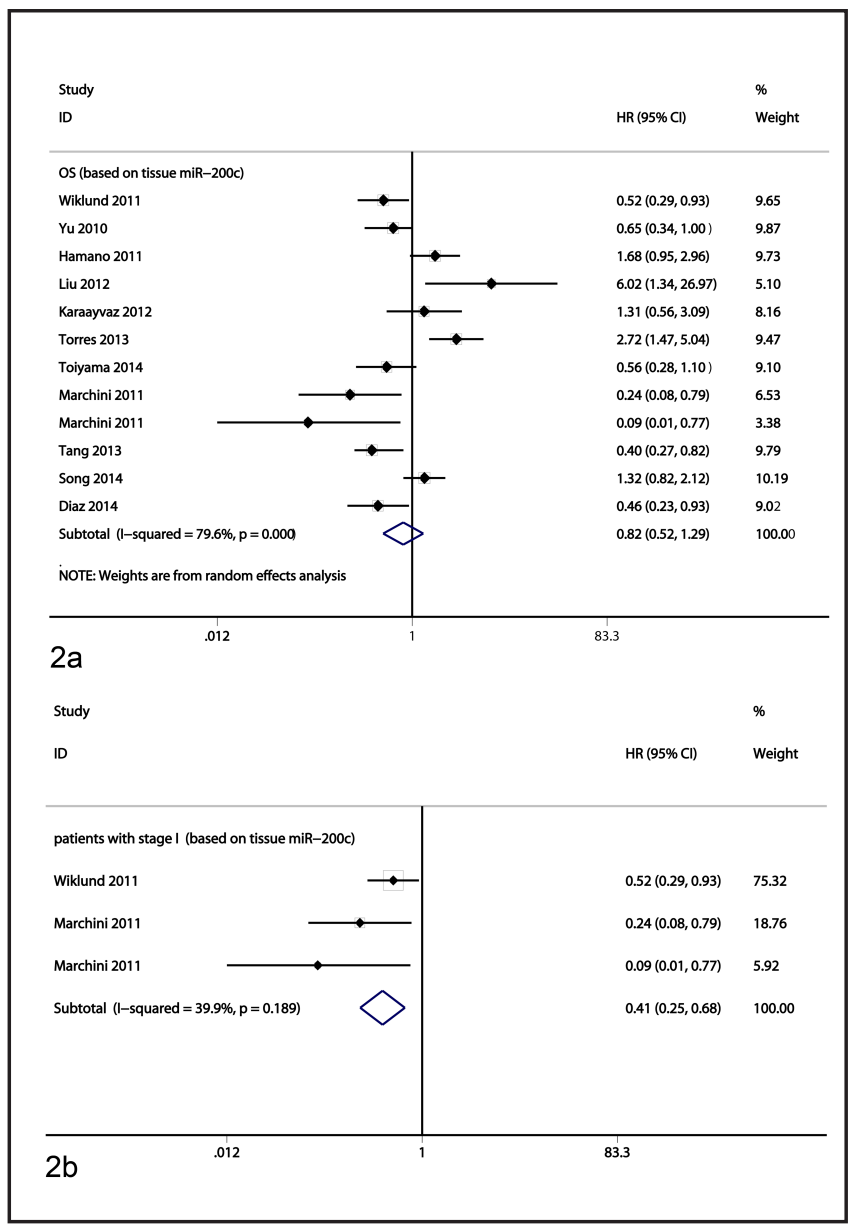

19, 20, 27]. 22 of the 25 studies assessed miR-200c expression by quantitative real-time polymerase chain reaction (qRT-PCR), a widely used method for miRNA quantitation. The cut-off values of normal miRNA levels were different in each study, and included median, mean, quartile, maximum normal tissue expression value and others.

However, 7 of the 23 articles were excluded because they did not have a large enough sample size, or did not provide sufficient data to calculate the HRs and 95\% CIs, or did not 
Table 3. The pooled associations between different groups of miR-200c overexpression and the prognosis of patients. qRT-PCR - quantitative real-time PCR, ISH - in situ hybridization, OS - overall survival, DFS disease-free survival, PFS - progression-free survival, HR - hazard ratio, CI - confidence interval, fixed - fixedeffects model, random - random-effects model.

\begin{tabular}{|c|c|c|c|c|c|c|c|c|}
\hline \multirow[t]{2}{*}{ Outcome subgroup (sample type) } & \multirow[t]{2}{*}{ No. of patients } & \multirow[t]{2}{*}{ No. of studies } & \multirow[t]{2}{*}{ HR (95\%CI) - model } & \multirow[t]{2}{*}{$P$ value } & \multicolumn{2}{|c|}{ heterogeneity } & \multicolumn{2}{|c|}{ Publication bias } \\
\hline & & & & & $I^{2}(\%)$ & $P$ & Begg's $P$ & Egger's $P$ \\
\hline OS (tissue) & 1405 & 12 & $0.82(0.52-1.29)$ - random & 0.382 & 79.6 & $<0.001$ & 0.631 & 0.653 \\
\hline \multicolumn{9}{|l|}{ Tumor stage } \\
\hline All patients with stage I & 244 & 3 & $0.41(0.25-0.68)-$ fixed & $0.001^{*}$ & 39.3 & 0.189 & 0.117 & 0.061 \\
\hline Patients with others stages & 1161 & 9 & $1.04(0.64-1.69)$ - random & 0.884 & 80.4 & $<0.001$ & 0.754 & 0.518 \\
\hline \multicolumn{9}{|l|}{ Tumor type } \\
\hline Endometrial cancer & 121 & 2 & $2.12(1.29-3.49)$ - fixed & $0.003^{*}$ & 46.1 & 0.173 & - & - \\
\hline Colorectal cancer & 283 & 2 & $0.51(0.31-0.83)$ - fixed & $0.007^{*}$ & 0 & 0.693 & - & - \\
\hline Gastric cancer & 490 & 2 & $0.73(0.23-2.36)$ - random & 0.603 & 90.2 & 0.001 & - & - \\
\hline Ovarian cancer & 144 & 2 & $0.19(0.07-0.54)-$ fixed & $0.002^{*}$ & 0 & 0.433 & - & - \\
\hline \multicolumn{9}{|l|}{ MiR-200c assay method } \\
\hline qRT-PCR & 1179 & 10 & $0.94(0.57-1.56)$ - random & 0.810 & 78.0 & $<0.001$ & 0.371 & 0.466 \\
\hline ISH & 226 & 2 & $0.45(0.3-0.68)-$ fixed & $<0.001^{*}$ & 0 & 0.523 & - & - \\
\hline \multicolumn{9}{|l|}{ Analysis type } \\
\hline Multivariate & 933 & 7 & $0.64(0.33-1.22)$ - random & 0.173 & 83.5 & $<0.001$ & 0.368 & 0.253 \\
\hline Univariate & 472 & 5 & $1.12(0.56-2.22)$ - random & 0.753 & 75.9 & 0.002 & 0.462 & 0.344 \\
\hline DFS (tissue) & 253 & 2 & $0.52(0.37-0.73)-$ fixed & $<0.001^{*}$ & 0 & 0.884 & - & - \\
\hline PFS (tissue) & 508 & 3 & $0.36(0.09-1.52)$ - random & 0.156 & 81.9 & 0.004 & 0.117 & 0.087 \\
\hline OS (blood) & 659 & 5 & $3.07(1.58-5.96)$ - random & $0.001^{*}$ & 82.6 & $<0.001$ & 0.086 & 0.158 \\
\hline \multicolumn{9}{|l|}{ Tumor stage } \\
\hline Advanced tumor patients & 607 & 4 & $3.36(1.46-7.71)$ - random & $0.004^{*}$ & 86.9 & $<0.001$ & 0.089 & 0.183 \\
\hline \multicolumn{9}{|l|}{ Analysis type } \\
\hline Multivariate & 398 & 3 & $1.91(1.40-2.59)$ - fixed & $<0.001^{*}$ & 0 & 0.482 & 0.296 & 0.151 \\
\hline Univariate & 261 & 2 & $5.79(0.91-36.96)$ - random & 0.064 & 92.7 & $<0.001$ & - & - \\
\hline PFS (blood) & 280 & 3 & $2.26(1.66-3.08)$ - fixed & $<0.001^{*}$ & 0 & 0.907 & 0.296 & 0.34 \\
\hline
\end{tabular}

belong to solid tumors of epithelial origin $[8,9,18,21,23,26,30]$. The article from Marchini et al. included two studies as it analyzed different cohorts [24], while Toiyama et al. analyzed the associations of both tissue and serum miR-200c with survival outcome [20]. So 18 studies were identified in the 16 articles and were enrolled into the meta-analysis (Fig. 1) [10-17, $19,20,22,24,25,27-29]$. It has been previously reported that there was no association between serum miR-200c and miR-200c in primary tumor tissue [20], thus we performed a meta-analysis based on both tissue and circulating miR-200c independently.

\section{Quality assessment}

Each of the 18 eligible studies included in our meta-analysis was assessed for quality according to the NOS. The quality of all studies included varied from 5 to 9 , with a mean of 6.6. A higher value indicated better methodology. Therefore, all studies were included in the subsequent analysis.

\section{Meta-analysis of tissue-based miR-200c overexpression}

Of 18 studies, 12 studies reported data of tissue miR-200c expression and the prognosis, which included 1,405 cancer patients. All the HRs and corresponding 95\% CIs from these articles are shown in Table 2. Based on the 12 studies providing OS of patients [10-14, 17, $20,24,25,28,29]$, a random model was used to calculate the pooled HR and its $95 \%$ CI due to the high heterogeneity between these studies $\left(P<0.001, I^{2}=79.6 \%\right)$ (Table 3$)$. The results showed that high expression of tissue miR-200c was not associated with favorable OS in various carcinomas, with the pooled HR of 0.82 (95\% CI 0.52-1.29, $P=0.382$ ) (Table 3; Fig. 2A). Because the two studies that reported DFS did not display obvious heterogeneity $\left(P=0.884, I^{2}=0 \%\right)$ (Table 3) $[25,29]$, we calculated the pooled HR using a fixed model. The pooled HR revealed that tissue miR-200c overexpression significantly predicted better DFS 
Fig. 3. Forest plots of studies evaluating hazard ratios of elevated blood-based miR-200c levels (a) Overall survival based on blood miR-200c. The survival data from 5 studies were pooled to calculate overall survival. (b) Progressionfree survival based on blood miR200c. The survival data from 3 records were pooled to calculate progression-free survival.

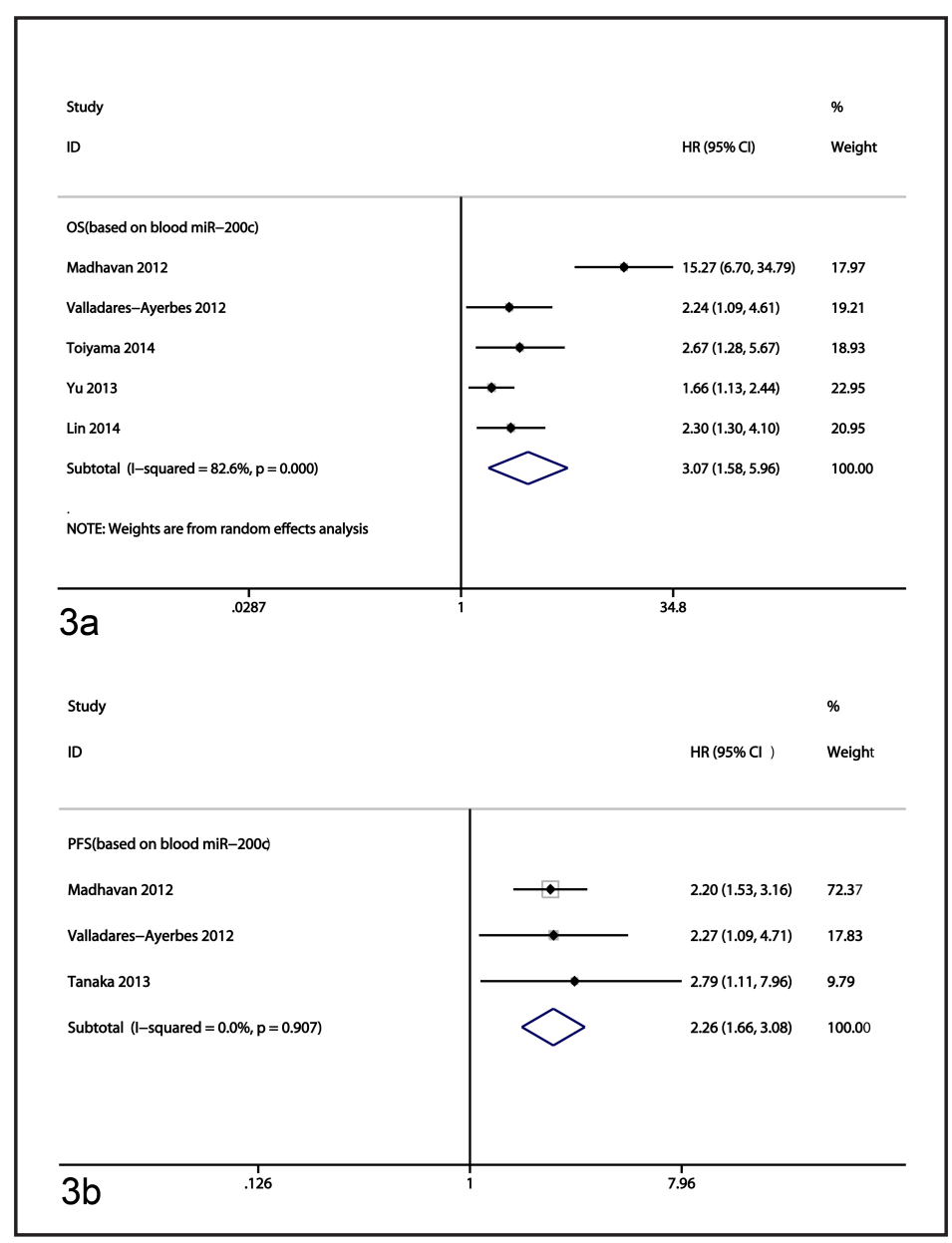

(HR=0.52, 95\% CI 0.37-0.73; $P<0.001$ ) (Table 3). Data from three studies that reported PFS $[24,28]$ revealed no correlation between high miR-200c level in tissue and better PFS (HR=0.36, 95\% CI 0.09-1.52, $P=0.156$, random-effects model; $P=0.004$ for heterogeneity test, $I^{2}=81.9 \%$ ) (Table 3).

Four subgroup analyses were performed that stratified patients by tumor type, stage, miR-200c assay method and analysis type. All the pooled HRs and corresponding 95\% CIs of the subgroups are shown in Table 3. In the subgroup analysis of patients with stage I cancer, the pooled HR indicated that low tissue miR-200c levels were significantly associated with poor OS (HR=0.41, 95\% CI $0.25-0.68$, fixed-effects model; $P=0.189$ for heterogeneity test, $I^{2}=39.3 \%$ ) (Table 3, Fig. 2B). This conclusion was also found in other subgroups of colorectal cancer, ovarian cancer and ISH assay method used. However, the subgroup analysis of endometrial cancer indicated the opposite result. We did not find any significant association between miR-200c and prognosis in subgroups of patients with other stages, gastric cancer, qRT-PCR assay method used, multivariate or univariate analysis.

\section{Meta-analysis of blood-based miR-200c overexpression}

A total of six studies encompassing 723 tumor patients focused on blood miR-200c expression and the prognosis of patients [15, 16, 19, 20,22,27]. All the HRs and corresponding 95\% CIs are shown in Table 4. Five of six studies reported OS and displayed significant heterogeneity among them $\left(P<0.001, I^{2}=82.6 \%\right)$ (Table 3$)[15,16,20,22,27]$. Therefore, a random model was applied to overall data integration, and we found that patients with high miR-200c levels in blood had a significantly poorer OS (HR=3.07, 95\% CI 1.58-5.96; $P=0.001$ ) (Table 3; Fig. 3A). Because the three studies that reported PFS were not of obvious 


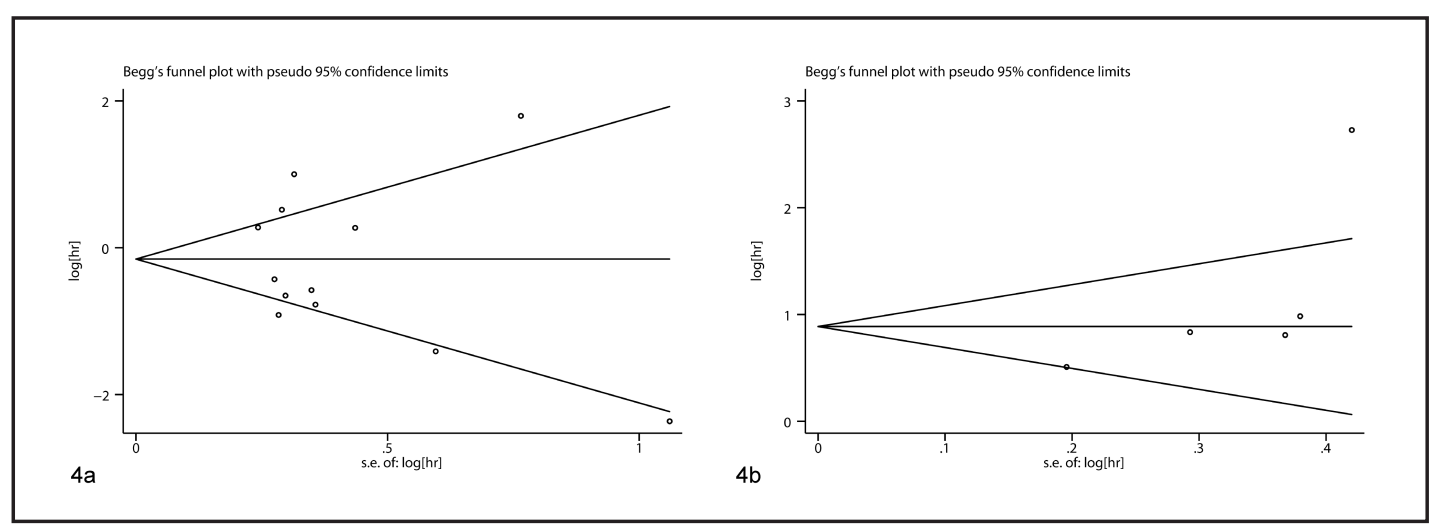

Fig. 4. Funnel plots of studies included in the two meta-analyses (a) overall survival based on tissue miR200c (b) overall survival based on blood miR-200c.

Table 4. HRs and corresponding 95\% CIs of eligible studies in the meta-analysis according to bloodbased miR-200c overexpression. qRT-PCR - quantitative real-time PCR, OS - overall survival PFS - progression-free survival, HR - hazard ratio, CI - confidence interval, NR - not reported, Ref. - reference.

\begin{tabular}{llcccc}
\hline Study & Tumor type & MiR-200c assay & $\begin{array}{c}\text { OS } \\
\text { HR }(95 \% \mathrm{Cl})\end{array}$ & $\begin{array}{c}\text { PFS } \\
\text { HR (95\% CI) }\end{array}$ & Ref. \\
\hline Madhavan 2012 & breast cancer & qRT-PCR & $15.27(6.7,34.79)$ & $2.2(1.53,3.16)$ & {$[15]$} \\
Valladares Ayerbes 2012 & gastric cancer & qRT-PCR & $2.24(1.091,4.614)$ & $2.27(1.093,4.712)$ & {$[16]$} \\
Tanaka 2013 & esophageal cancer & qRT-PCR & & $2.787(1.1079,7.9585)$ & {$[19]$} \\
Toiyama 2014 & colorectal cancer & qRT-PCR & $2.67(1.28,5.67)$ & NR & {$[20]$} \\
Yu 2013 & esophageal cancer & qRT-PCR & $1.665(1.135,2.443)$ & NR & {$[27]$} \\
Lin 2014 & prostate cancer & qRT-PCR & $2.30(1.30,4.10)$ & NR & {$[22]$} \\
\hline
\end{tabular}

heterogeneity $\left(P=0.907, I^{2}=0 \%\right)$ (Table 3$)[15,16,19]$, they were analyzed via a fixed model and the pooled HR revealed a significant positive association between high level of miR200c in blood and poor PFS (HR=2.26, 95\% CI 1.66-3.08, $P<0.001$ ) (Table 3; Fig. 3B). In the subgroup analysis of patients with advanced tumors, the pooled HR also indicated that high blood miR-200c level was significantly associated with poor OS (HR=3.36, 95\% CI 1.46-7.71, random-effects model; $P<0.001$ for heterogeneity test, $\left.I^{2}=86.9 \%\right)$. This conclusion was also found in the subgroup of multivariate analysis (HR=1.91, 95\% CI 1.40-2.59, $P<0.001$ ), but not in univariate analysis subgroup ( $\mathrm{HR}=5.79,95 \% \mathrm{CI} 0.91-36.96, P=0.064)$.

\section{Heterogeneity Analysis}

There was clear heterogeneity in 9 of the 16 analysis groups, as shown in Table 3 . The heterogeneity in the OS analysis group based on tissue miR-200c, which included 12 studies, was obvious $\left(P<0.001, I^{2}=79.6 \%\right)$, thus, a meta-regression was conducted to explore the factors that induced the obvious heterogeneity. As a result, the obvious heterogeneity was induced by tumor stage $(P=0.044)$ rather than tumor type $(P=0.170)$, analysis type $(P=0.294)$, miR-200c assay method ( $P=0.344)$, patients origin $(P=0.422)$, follow-up time $(P=0.378)$, cutoff values $(P=0.804)$ and publication year $(P=0.916)$.

\section{Publication Bias}

The publication bias of all enrolled studies was evaluated using funnel plots, and Egger's and Begg's tests. The funnel plots of the OS analysis based on tissue and blood miR-200c were almost symmetric, as shown in Fig. 4. In the 16 analysis groups, the $P$ values of Egger's and Begg's tests were all greater than 0.05 (Table 3). Hence, significant publication bias was not observed in our meta-analysis. 


\section{Discussion}

Metastasis is the spread of tumor cells from a primary tumor to a secondary site, and it remains the cause of $90 \%$ of deaths of cancer patients. Tumor metastasis is achieved by a series of intricate steps, including cell dissociation from the primary lesion, invasion into blood or lymphatic vessels, survival as microembolus in the circulatory system, extravasation and the formation of macroscopic foci in distant organs [37-39]. These steps are sequential and interrelated, and a failure or an insufficiency at any step can prevent the completion of metastasis. One of the key molecular steps in the process of distant metastasis is EMT, which permits invasion and emigration in various cancers [40,41]. EMT is a complex process by which epithelial cells lose their epithelial cancer cell characteristics, but acquire a mesenchymal phenotype that is characterized by cell skeleton reorganization, motility, invasiveness and a heightened resistance to apoptosis [42]. Thus, EMT is thought to initiate early events of metastatic dissemination in carcinomas. The expression of cellular adhesion proteins such as E-cadherin and $\gamma$-catenin is significantly downregulated during the EMT process, while the expression of mesenchymal markers such as vimentin and $\mathrm{N}$-cadherin is upregulated. [6]. The functional loss of E-cadherin is a well-known hallmark of EMT and is accomplished generally through altered expression of the CDH1 transcriptional repressors, such as ZEB1/2, SNAI1/2, Twist1/2 and others [43-46]. In physiological conditions, the shift from EMT to MET is a necessary step in tissue construction. Similar to metastasis, tumor cells also undergo MET to facilitate the establishment of macroscopic metastases [42, 47, 48].

The miR-200 family members play an important role in regulating metastasis. Particularly, miR-200c plays critical roles in inhibiting EMT and promoting MET by direct targeting of E-cadherin transcriptional repressors ZEB1 and ZEB2. It is well documented that highly expressed miR-200c in epithelial cancer cells represses the expression of ZEBs, whereas impaired expression of miR-200c in mesenchymal cancer cells leads to upregulation of ZEBs and induces downregulation of E-cadherin [2-4, 49]. Some studies have revealed that the expression of miR-200c is impaired in various human tumors, such as bladder cancer, gastric cancer, pancreatic cancer, esophageal cancer, colorectal cancer and ovarian cancer, thereby inducing EMT and disease progression [10, 11, 24, 25, 27, 29, 50]. In addition, miR200c plays a crucial role in regulating stem cell self-renewal and differentiation. By targeting B lymphoma Mo-MLV insertion region 1 homolog (BMI1), a known regulator for stem cell self-renewal, miR-200c strongly suppresses the ability of normal mammary stem cells to form mammary ducts and decreases tumor formation driven by human breast cancer stem cells (CSCs) in vivo [51]. These data collectively indicate that the miR-200c may act as a tumor suppressor. However, upregulation of miR-200c has been found in multiple tumors including NSCLC, breast cancer, ovarian cancer and endometrial cancer $[9,13,15,17,52]$, indicating that miR-200c may also exhibit oncogenic potential, likely due to over expression of miR-200c increasing metastatic risk by the induction of MET. Thus, it is controversial miR200c expression can be used as a prognostic biomarker in different cancers.

Recently, a meta-analysis reported by Wang et al. [53] assessed the correlation between miR-200c and prognosis of patients with malignant tumors, and the results demonstrated that low expression of miR-200c in tumor tissue and high expression of miR-200c in serum were associated with worse survival in solid tumors. However, its search of relevant literature was limited to PubMed and just contained 6 articles. Obviously, it's not comprehensive enough to collect all relevant evidence available from the literature, and the strength of their conclusions was doubtful. In this study, we search the literature through PubMed, Embase and the Cochrane Library, and 19 articles are enrolled. The conclusion of this meta-analysis is different from Wang et al.'s, and we believe it is more powerfully evidence-based and credible. In this systemic review and meta-analysis, all the studies that reported the prognostic value of miR-200c in patients with malignant tumors did not come to an accordant conclusion. In this systematic review, we found that low expression of tissue miR-200c was a negative prognostic factor in groups consisted mainly of early cancer patients. With the increased 
ratio of patients with advanced tumors in investigative subjects, the prognostic value of tissue miR-200c became less or even inexistent. However, when patients with advanced tumors dominated in the investigative group, high expression of miR-200c became a negative prognostic factor. This phenomenon demonstrates that the effect of miR-200c on the prognosis of cancer patients may be a process of dynamic change with different progression stages of tumor. Our future meta-analysis confirmed that although there was no relationship between tissue miR-200c expression and the prognosis of all patients regardless of tumor stage, low expression level of miR-200c in primary tumor tissue was associated with poor prognosis of patients with stage I cancer. In such early stage, metastasis has not yet started, so it is necessary for tumor cells to undergo EMT as an initiating event of metastasis. Given the suppressive effect of miR-200c on EMT, tumors with low miR-200c expression have increased potential of invasion and metastasis by promoting EMT, ultimately leading to poor prognosis of patients. We also found that high blood miR-200c level was associated with poor OS and PFS. However the quantity of patients with early disease is too small, and there is no special study which researches only early stage patients. Although there is no hard evidence to support the relationship between blood miR-200c expression and early stage patients' outcome, the results of the subgroup analysis bases on patients with advanced disease demonstrated that overexpression of blood miR-200c predict poor prognosis in patients with advanced tumors. This interesting result may confirm the following hypothesis. During the process of tumor metastasis, miR-200c is initially silenced to change cell behaviors that induce tumor cells to escape from the primary sites. It is then upregulated to reverse the metastatic phenotype and facilitate local growth of metastatic lesions. Advanced tumors are typically accompanied by lymphovascular invasion and have accomplished the first step of metastasis via EMT. MET is subsequently necessary to accomplish the final step of colonization. High levels of miR-200c in blood can be viewed as a critical promoter of MET that induces circulating tumor cells to form macroscopic metastatic nodules. Therefore, we speculate that the prognosis of patients with advanced tumors is influenced by miR-200c in blood more than miR-200c in primary tissue. Toiyama et al. reported that the expression status of miR-200c in serum was consistent with metastatic tissue, but inconsistent with that in primary tissue $[7,20]$. This result also supports the theory we propose here: the expression of miR-200c in primary tissue and blood can be a valuable prognostic biomarker for patients with early stage and advanced tumors, respectively.

However, some details need to be further refined. First, this study only included only 18 eligible studies, which resulted in relatively insufficiency data in the subgroup analyses. Second, due to the lack of a unified cut-off value in miR-200c expression, different cut-off values were used in those studies. The inaccurate cut-off values may affect the availability of miR-200c as a predictive biomarker in cancer prognosis. Third, several HRs were calculated based on the data extracted from the survival curves, which inevitably leads to small statistical errors. Fourth, there was significant heterogeneity displayed in our meta-analysis and most likely due to variation in patient origin, publication year, tumor type, tumor stage, miR-200c assay method, analysis type, follow-up time, cut-off values among others. Finally, although there was no significant publication bias found in this meta-analysis, the sample size was still not large enough to determine the existence of publication bias.

\section{Conclusion}

In conclusion, we found that low expression of miR-200c in primary tissue was significantly associated with poor survival in cancer patients at an early stage of disease, whereas high level of miR-200c in blood could predict poor prognosis in patients with advanced tumors. Considering the limitations of present analysis, the conclusions should be regarded cautiously. Further prospective multi-center studies with larger sample size are needed to test the association between miR-200c and cancer prognosis, as well as to explore effective therapies. Besides, the results of this meta-analysis also suggest the opposite effects 
of miR-200c in tumor local infiltration and distant metastasis via the process of EMT and MET, respectively: the low expression of miR-200c in early tumor tissues promotes EMT and increases potential of invasion, but the high level of blood miR-200c in advanced cases contributes to MET and the establishment of macroscopic metastasis. This theory requires further investigations to explore the potential mechanism.

\section{Acknowledgements}

This research project was supported by the National Natural Science Foundation of China (NSFC) (81171653) and the General Program of Jiangsu Province Department of Health (H201350).

\section{Disclosure Statement}

The authors declare that they have no conflict of interest.

\section{Reference}

1 Di Leva G, Croce CM: miRNA profiling of cancer. Curr Opin Genet Dev 2013;23:3-11.

- Gregory PA, Bert AG, Paterson EL, Barry SC, Tsykin A, Farshid G, Vadas MA, Khew-Goodall Y, Goodall GJ: The miR-200 family and miR-205 regulate epithelial to mesenchymal transition by targeting ZEB1 and SIP1.

Nat Cell Biol 2008;10:593-601.

-3 Park SM, Gaur AB, Lengyel E, Peter ME: The miR-200 family determines the epithelial phenotype of cancer cells by targeting the E-cadherin repressors ZEB1 and ZEB2. Genes Dev 2008;22:894-907.

4 Hurteau GJ, Carlson JA, Roos E, Brock GJ: Stable expression of miR-200c alone is sufficient to regulate TCF8 (ZEB1) and restore E-cadherin expression. Cell Cycle 2009;8:2064-2069.

-5 Korpal M, Ell BJ, Buffa FM, Ibrahim T, Blanco MA, Celia-Terrassa T, Mercatali L, Khan Z, Goodarzi H, Hua Y, Wei Y, Hu G, Garcia BA, Ragoussis J, Amadori D, Harris AL, Kang Y: Direct targeting of Sec23a by miR-200s influences cancer cell secretome and promotes metastatic colonization. Nat Med 2011;17:1101-1108.

6 Thiery JP, Sleeman JP: Complex networks orchestrate epithelial-mesenchymal transitions. Nat Rev Mol Cell Biol 2006;7:131-142.

-7 Hur K, Toiyama Y, Takahashi M, Balaguer F, Nagasaka T, Koike J, Hemmi H, Koi M, Boland CR, Goel A: MicroRNA-200c modulates epithelial-to-mesenchymal transition (EMT) in human colorectal cancer metastasis. Gut 2013;62:1315-1326.

-8 Xi Y, Formentini A, Chien M, Weir DB, Russo JJ, Ju J, Kornmann M: Prognostic Values of microRNAs in Colorectal Cancer. Biomark Insights 2006;2:113-121.

-9 Nam EJ, Yoon H, Kim SW, Kim H, Kim YT, Kim JH, Kim JW, Kim S: MicroRNA expression profiles in serous ovarian carcinoma. Clin Cancer Res 2008;14:2690-2695.

10 Wiklund ED, Bramsen JB, Hulf T, Dyrskjot L, Ramanathan R, Hansen TB, Villadsen SB, Gao S, Ostenfeld MS, Borre M, Peter ME, Orntoft TF, Kjems J, Clark SJ: Coordinated epigenetic repression of the miR-200 family and miR-205 in invasive bladder cancer. Int J Cancer 2011;128:1327-1334.

11 Yu J, Ohuchida K, Mizumoto K, Sato N, Kayashima T, Fujita H, Nakata K, Tanaka M: MicroRNA, hsa-miR200c, is an independent prognostic factor in pancreatic cancer and its upregulation inhibits pancreatic cancer invasion but increases cell proliferation. Mol Cancer 2010;9:169.

12 Hamano R, Miyata H, Yamasaki M, Kurokawa Y, Hara J, Moon JH, Nakajima K, Takiguchi S, Fujiwara Y, Mori M, Doki Y: Overexpression of miR-200c induces chemoresistance in esophageal cancers mediated through activation of the Akt signaling pathway. Clin Cancer Res 2011;17:3029-3038.

13 Liu XG, Zhu WY, Huang YY, Ma LN, Zhou SQ, Wang YK, Zeng F, Zhou JH, Zhang YK: High expression of serum miR-21 and tumor miR-200c associated with poor prognosis in patients with lung cancer. Med Oncol 2012;29:618-626.

14 Karaayvaz M, Zhang C, Liang S, Shroyer KR, Ju J: Prognostic significance of miR-205 in endometrial cancer. PLoS One 2012;7:e35158. 


\section{Cellular Physiology Cell Physiol Biochem 2015;35:1188-1200 \begin{tabular}{l|l} 
DOI: 10.1159/000373943 & (c) 2015 S. Karger AG, Basel
\end{tabular}

-15 Madhavan D, Zucknick M, Wallwiener M, Cuk K, Modugno C, Scharpff M, Schott S, Heil J, Turchinovich A, Yang R, Benner A, Riethdorf S, Trumpp A, Sohn C, Pantel K, Schneeweiss A, Burwinkel B: Circulating miRNAs as surrogate markers for circulating tumor cells and prognostic markers in metastatic breast cancer. Clin Cancer Res 2012;18:5972-5982.

-16 Valladares-Ayerbes M, Reboredo M, Medina-Villaamil V, Iglesias-Diaz P, Lorenzo-Patino MJ, Haz M, Santamarina I, Blanco M, Fernandez-Tajes J, Quindos M, Carral A, Figueroa A, Anton-Aparicio LM, Calvo L: Circulating miR-200c as a diagnostic and prognostic biomarker for gastric cancer. J Transl Med 2012;10:186.

17 Torres A, Torres K, Pesci A, Ceccaroni M, Paszkowski T, Cassandrini P, Zamboni G, Maciejewski R: Diagnostic and prognostic significance of miRNA signatures in tissues and plasma of endometrioid endometrial carcinoma patients. Int J Cancer 2013;132:1633-1645.

18 Berglund M, Hedstrom G, Amini RM, Enblad G, Thunberg U: High expression of microRNA-200c predicts poor clinical outcome in diffuse large B-cell lymphoma. Oncol Rep 2013;29:720-724.

19 Tanaka K, Miyata H, Yamasaki M, Sugimura K, Takahashi T, Kurokawa Y, Nakajima K, Takiguchi S, Mori M, Doki Y: Circulating miR-200c levels significantly predict response to chemotherapy and prognosis of patients undergoing neoadjuvant chemotherapy for esophageal cancer. Ann Surg Oncol 2013;20:S607-615.

20 Toiyama Y, Hur K, Tanaka K, Inoue Y, Kusunoki M, Boland CR, Goel A: Serum miR-200c Is a Novel Prognostic and Metastasis-Predictive Biomarker in Patients With Colorectal Cancer. Ann Surg 2014;259:735-743.

21 Vilming Elgaaen B, Olstad OK, Haug KB, Brusletto B, Sandvik L, Staff AC, Gautvik KM, Davidson B: Global miRNA expression analysis of serous and clear cell ovarian carcinomas identifies differentially expressed miRNAs including miR-200c-3p as a prognostic marker. BMC Cancer 2014;14:80.

22 Lin HM, Castillo L, Mahon KL, Chiam K, Lee BY, Nguyen Q Boyer MJ, Stockler MR, Pavlakis N, Marx G, Mallesara G, Gurney H, Clark SJ, Swarbrick A, Daly RJ, Horvath LG: Circulating microRNAs are associated with docetaxel chemotherapy outcome in castration-resistant prostate cancer. Br J Cancer 2014;110:24622471.

23 Leskela S, Leandro-Garcia LJ, Mendiola M, Barriuso J, Inglada-Perez L, Munoz I, Martinez-Delgado B, Redondo A, de Santiago J, Robledo M, Hardisson D, Rodriguez-Antona C: The miR-200 family controls betatubulin III expression and is associated with paclitaxel-based treatment response and progression-free survival in ovarian cancer patients. Endocr Relat Cancer 2011;18:85-95.

24 Marchini S, Cavalieri D, Fruscio R, Calura E, Garavaglia D, Nerini IF, Mangioni C, Cattoretti G, Clivio L, Beltrame L, Katsaros D, Scarampi L, Menato G, Perego P, Chiorino G, Buda A, Romualdi C, D'Incalci M: Association between miR-200c and the survival of patients with stage I epithelial ovarian cancer: a retrospective study of two independent tumour tissue collections. Lancet Oncol 2011;12:273-285.

25 Tang H, Deng M, Tang Y, Xie X, Guo J, Kong Y, Ye F, Su Q: miR-200b and miR-200c as prognostic factors and mediators of gastric cancer cell progression. Clin Cancer Res 2013;19:5602-5612.

26 Yeh TS, Wang F, Chen TC, Yeh CN, Yu MC, Jan YY, Chen MF: Expression profile of microRNA-200 family in hepatocellular carcinoma with bile duct tumor thrombus. Ann Surg 2014;259:346-354.

27 Yu H, Duan B, Jiang L, Lin M, Sheng H, Huang J, Gao H: Serum miR-200c and clinical outcome of patients with advanced esophageal squamous cancer receiving platinum-based chemotherapy. Am J Transl Res 2013;6:71-77.

28 Song F, Yang D, Liu B, Guo Y, Zheng H, Li L, Wang T, Yu J, Zhao Y, Niu R, Liang H, Winkler H, Zhang W, Hao $\mathrm{X}$, Chen K: Integrated microRNA network analyses identify a poor-prognosis subtype of gastric cancer characterized by the miR-200 family. Clin Cancer Res 2014;20:878-889.

-29 Diaz T, Tejero R, Moreno I, Ferrer G, Cordeiro A, Artells R, Navarro A, Hernandez R, Tapia G, Monzo M: Role of miR-200 family members in survival of colorectal cancer patients treated with fluoropyrimidines. J Surg Oncol 2014;109:676-683.

- 30 Bhangu A, Wood G, Brown G, Darzi A, Tekkis P, Goldin R: The role of epithelial mesenchymal transition and resistance to neoadjuvant therapy in locally advanced rectal cancer. Colorectal Dis 2014;16:0133-143.

- 31 Stroup DF, Berlin JA, Morton SC, Olkin I, Williamson GD, Rennie D, Moher D, Becker BJ, Sipe TA, Thacker SB: Meta-analysis of observational studies in epidemiology: a proposal for reporting. Meta-analysis Of Observational Studies in Epidemiology (MOOSE) group. JAMA 2000;283:2008-2012.

-32 Stang A: Critical evaluation of the Newcastle-Ottawa scale for the assessment of the quality of nonrandomized studies in meta-analyses. Eur J Epidemiol 2010;25:603-605. 


\section{Cellular Physiology Cell Physiol Biochem 2015;35:1188-1200 \begin{tabular}{l|l} 
and Biochemistry Publisned onlIne: February 10, 2015 & $\begin{array}{l}\text { C) } 2015 \text { S. Karger AG, Basel } \\
\text { www.karger.com/cpb }\end{array}$
\end{tabular}

33 Tierney JF, Stewart LA, Ghersi D, Burdett S, Sydes MR: Practical methods for incorporating summary timeto-event data into meta-analysis. Trials 2007;8:16.

-34 Higgins JP, Thompson SG: Quantifying heterogeneity in a meta-analysis. Stat Med 2002;21:1539-1558.

-35 Higgins JP, Thompson SG, Deeks JJ, Altman DG: Measuring inconsistency in meta-analyses. BMJ 2003;327:557-560.

-36 Duval S, Tweedie R: Trim and fill: A simple funnel-plot-based method of testing and adjusting for publication bias in meta-analysis. Biometrics 2000;56:455-463.

- 37 Chaffer CL, Weinberg RA: A perspective on cancer cell metastasis. Science 2011;331:1559-1564.

-38 Yilmaz M, Christofori G: EMT, the cytoskeleton, and cancer cell invasion. Cancer Metastasis Rev 2009;28:15-33.

- 39 Geiger TR, Peeper DS: Metastasis mechanisms. Biochim Biophys Acta 2009;1796:293-308.

40 Yang J, Weinberg RA: Epithelial-mesenchymal transition: at the crossroads of development and tumor metastasis. Dev Cell 2008;14:818-829.

41 Wang Y, Shang Y: Epigenetic control of epithelial-to-mesenchymal transition and cancer metastasis. Exp Cell Res 2013;319:160-169.

42 Polyak K, Weinberg RA: Transitions between epithelial and mesenchymal states: acquisition of malignant and stem cell traits. Nat Rev Cancer 2009;9:265-273.

43 Cano A, Perez-Moreno MA, Rodrigo I, Locascio A, Blanco MJ, del Barrio MG, Portillo F, Nieto MA: The transcription factor snail controls epithelial-mesenchymal transitions by repressing E-cadherin expression. Nat Cell Biol 2000;2:76-83.

-44 Comijn J, Berx G, Vermassen P, Verschueren K, van Grunsven L, Bruyneel E, Mareel M, Huylebroeck D, van Roy F: The two-handed E box binding zinc finger protein SIP1 downregulates E-cadherin and induces invasion. Mol Cell 2001;7:1267-1278.

-45 Eger A, Aigner K, Sonderegger S, Dampier B, Oehler S, Schreiber M, Berx G, Cano A, Beug H, Foisner R: DeltaEF1 is a transcriptional repressor of E-cadherin and regulates epithelial plasticity in breast cancer cells. Oncogene 2005;24:2375-2385.

46 Kang Y, Massague J: Epithelial-mesenchymal transitions: twist in development and metastasis. Cell 2004;118:277-279.

47 Berx G, Raspe E, Christofori G, Thiery JP, Sleeman JP: Pre-EMTing metastasis? Recapitulation of morphogenetic processes in cancer. Clin Exp Metastasis 2007;24:587-597.

48 Baum B, Settleman J, Quinlan MP: Transitions between epithelial and mesenchymal states in development and disease. Semin Cell Dev Biol 2008;19:294-308.

49 Korpal M, Lee ES, Hu G, Kang Y: The miR-200 family inhibits epithelial-mesenchymal transition and cancer cell migration by direct targeting of E-cadherin transcriptional repressors ZEB1 and ZEB2. J Biol Chem 2008;283:14910-14914.

-50 Bendoraite A, Knouf EC, Garg KS, Parkin RK, Kroh EM, O'Briant KC, Ventura AP, Godwin AK, Karlan BY, Drescher CW, Urban N, Knudsen BS, Tewari M: Regulation of miR-200 family microRNAs and ZEB transcription factors in ovarian cancer: evidence supporting a mesothelial-to-epithelial transition. Gynecol Oncol 2010;116:117-125.

-51 Shimono Y, Zabala M, Cho RW, Lobo N, Dalerba P, Qian D, Diehn M, Liu H, Panula SP, Chiao E, Dirbas FM, Somlo G, Pera RA, Lao K, Clarke MF: Downregulation of miRNA-200c links breast cancer stem cells with normal stem cells. Cell 2009;138:592-603.

52 Snowdon J, Zhang X, Childs T, Tron VA, Feilotter H: The microRNA-200 family is upregulated in endometrial carcinoma. PLoS One 2011;6:e22828.

53 Wang HY, Shen J, Jiang CP, Liu BR. How to explain the contradiction of microRNA 200c expression and survival in solid tumors? A meta-analysis. Asian Pac J Cancer Prev 2014;15:3687-3690. 